\title{
Designing of protective seaside wall composite elements for protection of roads along the seashore
}

\author{
A. E. Ushakov, Y. G. Klenin, A. V. Pankov \& S. N. Ozerov \\ Science and Technology Testing Center, ApATeCh-Dubna, Russia
}

\begin{abstract}
Preparation for the Sochi Olympic Games in 2014 requires new solutions in the building of seashore infrastructures. The building of a second track was organised along the seashore in order to expand and improve transport capacity. In order to protect the railway's embankment from the wash-out it was necessary to build protective walls along the seashore. For this purpose it was proposed by ApATeCh to use a new structure of protective seaside wall using FRP. "ApATeCh" has developed a conceptually new structure of sub-grade support combined with a protective seaside structure. The traditional materials used for this type of structure, such as concrete and stone, have been fully replaced by composite materials. Within the wall's designing process the complete cycle of calculation and experimental research has been executed for the confirmation of the wall's bearing capacity. In order to determine the actual loads of different elements of the protective wall, the system of strain-measuring monitoring was integrated inside the wall. In order to determine the possible deformation of the composite panels and of the whole structure, the method of engineering and geodesic monitoring was developed. The application of composite materials for the protective seaside wall enabled a substantial decrease in the installation period and expenses whilst increasing the service life of the structure by threefour times.
\end{abstract}

Keywords: emission sources, trace and heavy metal, anthropogenic activity, dust composition, elemental concentrations. 


\section{Introduction}

The large volumes of cargo that needed to be transported to Sochi for preparation for the Olympic Games in 2014 required a considerable increase of surface transport capacity. Landscape peculiarities of the Black Sea coast dictated that the problem could only be solved by building closely to the coast, which is why development of marine infrastructure is very important as well as sea coast protection from destructive wave and current impact, and improvement of the recreation properties of coasts. The existing concrete and natural stone structures are resource-intensive, and their service life is 20-30 years (fig. 1).

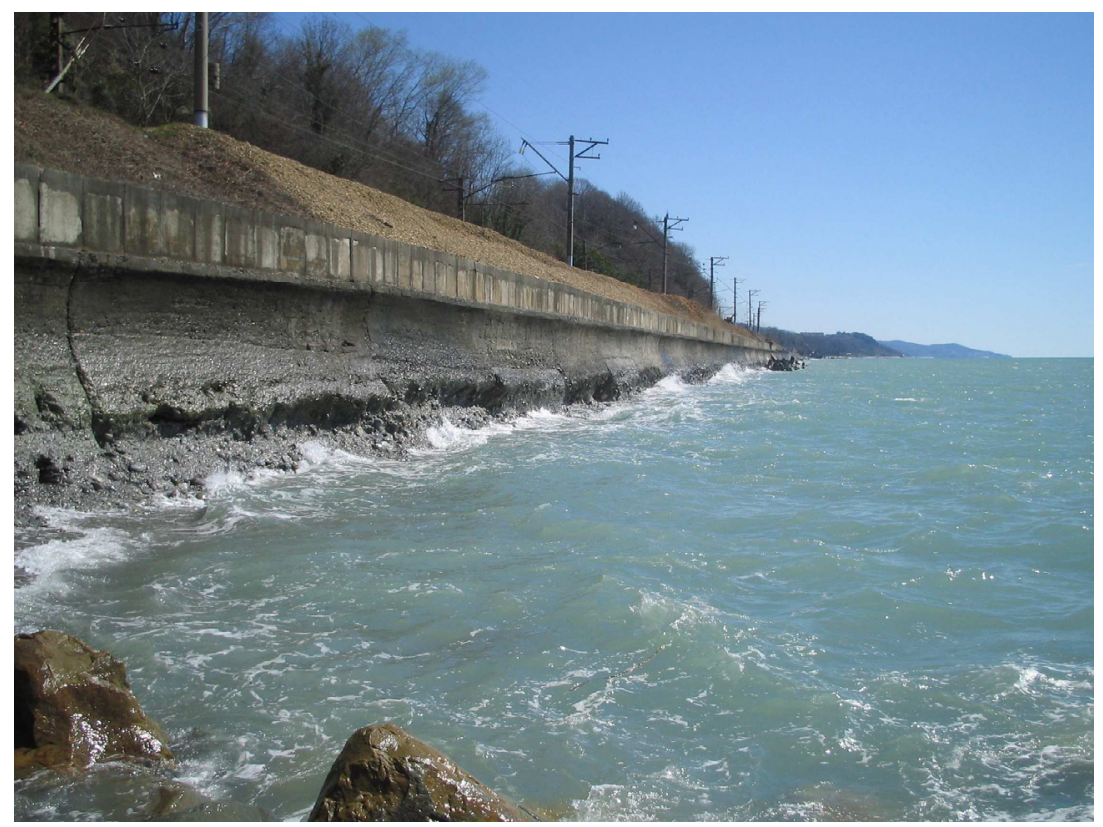

Figure 1: Typical destruction of the wall in operation.

The main task during erection of the seawalls, designated for building additional railroads, was the minimizing of materials and of the labor force which are presently in short supply. The following structure was used as a solution: the main part of the wall was made of reinforced soil (crushed stone), forming the manufactured solid monolith of wrapped non-woven geo-textile layers (geo-gratings) with crushed stone filling, protected from the impact of the sea by a composite side wall (covering). The covering is fastened to the reinforced soil by several rows of anchors. We will call this side wall (covering) 'composite wall', or just 'wall'.

In fig. 2 you can see the external appearance of the wall. 


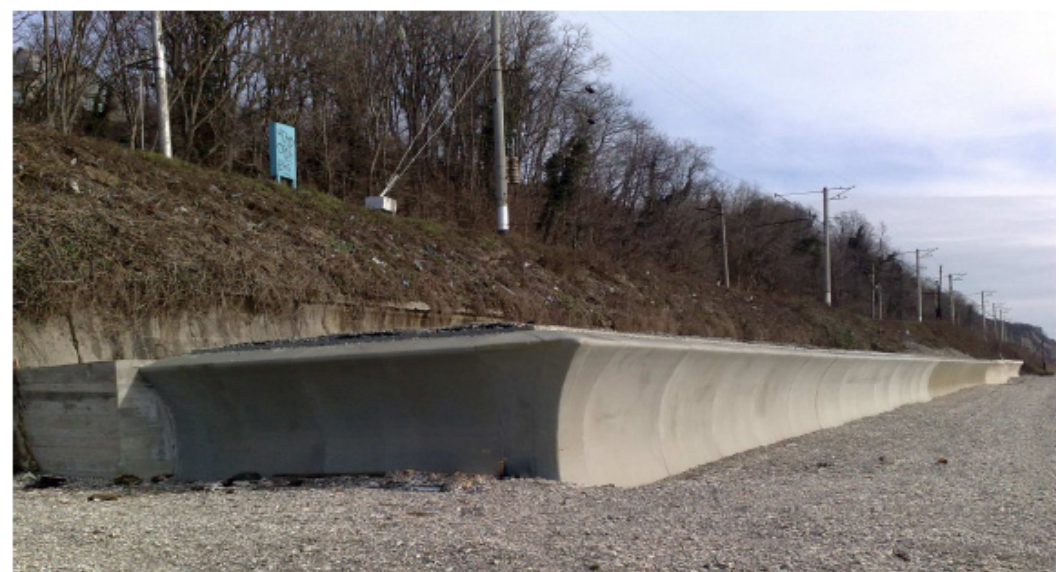

Figure 2: $\quad$ External appearance of the protective seaside wall.

\section{Technical requirements and load cases}

Due to the innovative nature of the structure's technical requirements to the side wall, load cases, necessary for the structure design, were absent. During operation the composite wall is exposed to:

- from the seaside - wave and wind loads;

- from the side of reinforced soil - theoretically the load is absent, as the slope angle of the covering is smaller than the angle of the internal friction of soil, but we cannot totally exclude the presence of irregular distortions of the soil along the length of the wall during operation and the presence of installation strength in the anchor bars.

Calculation of loads from the wave impact is executed in accordance with the requirements of building norms and rules 2.06.04-82* "Loads and impacts on

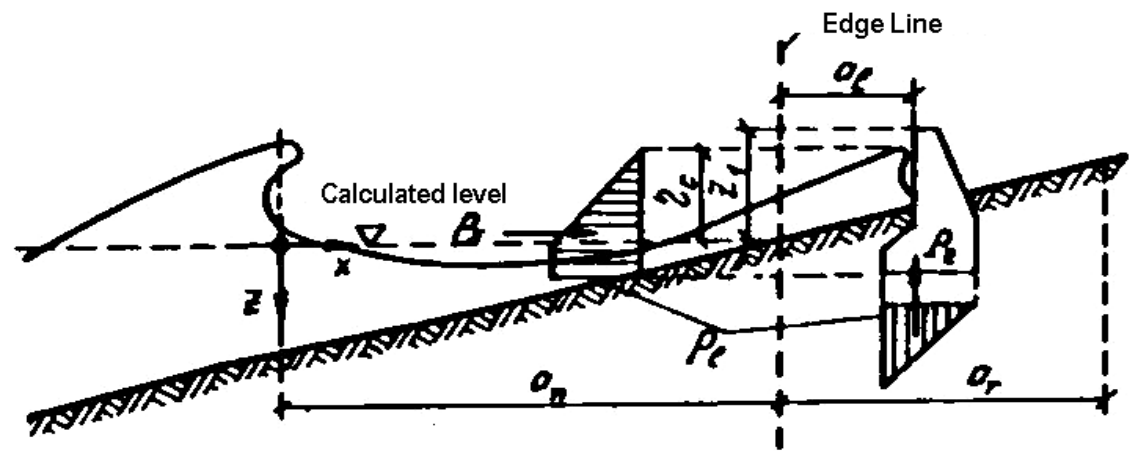

Figure 3: Diagram of wave pressure on the wall. 
the hydro technical buildings (wave, ice and from ships)" (in Russian). A diagram of wave pressure is given in fig. 3 .

For the estimation of wave impact on the protective sea structures the parameters of maximum waves were used, received on the basis of monitoring in the zone of wall installation (seashore section on the track side Tuapse-Schepsi: cape Kodosh-river Ashe) within 70,000 hours. The maximum pressure at the designated gravel and sand beach for the storm, forming in the Tuapse district one time in 25 years ( 8 numbers), is $\boldsymbol{p}_{\boldsymbol{l}}=6.2 \mathrm{kN} / \mathrm{m}^{2}$, and the wave height on the protective sea wall $-\eta=0.63 \mathrm{~m}$. At the washout of the beach during the storm to the height of up to $1.23 \mathrm{~m}$, the affected parameters of load diagrams from the wind load are $\boldsymbol{p}_{\boldsymbol{l}}=21.4 \mathrm{kN} / \mathrm{m}^{2}$ and $\boldsymbol{\eta}=2.12 \mathrm{~m}$. Maximum wind load for the wall installation zone is generally $400 \mathrm{~N} / \mathrm{m}^{2}$.

In an expert way, the following pressure diagrams of soil filling for different structure elements, has been fixed:

- for the wall elements which have minus angle in relation to vertical line (soil lays on the wall structure), maximal pressure $40 \mathrm{kN} / \mathrm{m}^{2}$;

- for the wall elements which have positive angle in relation to vertical line, there is no pressure from the soil;

In designing the composite wall, the following requirements were used:

- The wall is designed for the building of the second railway track without traffic interruption. The wall structure should provide the reduction of installation time of up to 8-10 times in comparison with concrete structures, and increase of service life of up to 70-100 years.

- The wall structure should be mobile in order to provide delivery of its elements to the assembly site. Structure of separate elements of the wall should enable them to be securely joined to each other after assembly and allow for the possibility of joints encapsulation of the panels. Fastening of the wall elements should prevent the possibility of unauthorized disassembly of the structure.

- Structure of protective sea wall should secure integrity of geometrical parameters and strength properties after influence of atmospheric fallout, solar radiation, waves, sea water, gravel and sand during the whole service life.

- Sea walls should be calculated to mechanical strength taking into consideration the above mentioned loads. The calculation is conducted excluding contact of wall with reinforcement soil. The bending of the wall on the section between attachment fitting of the anchors in accordance with the condition of providing the strength of the geotechnical grating should not exceed $6 \mathrm{~mm}$.

- It is necessary to cover the surface of the wall with a wear-resistant coating for prevention of erosion which arises due to the influence processes of sand and gravel.

- The coating should be applied in facility conditions on the separate panels. 
- For changing the wall direction, corner panels should be made and the temperature seams have to be generated for compensation of expansion joint.

- The protective wall should be made with a maximum application of fiberglass. It is assumed to apply the separate elements made of corrosionresistant steels, supposing operation in water.

- The material of the walls and structure should provide all functional requirements in the temperature range from $-30^{\circ}$ to $+70^{\circ} \mathrm{C}$ at operation in regions with moderate and tropical climate and also at direct contact with soil and seawater.

\subsection{Engineering}

On the basis of the mentioned requirements a structure of the wall panels, anchors and attachment fittings has been designed. The panels, with integrated attachment fittings, are produced from fiberglass by vacuum infusion technology, anchors bars - from pultrusion fiberglass profiles of plan section. The panels are connected between each other by flange joints with the use of stainless steel bolts. These bolts and plates in anchors are the only metal elements of a wall. Geometric parameters of the wall elements are determined by taking into consideration different combinations of the following load cases:

- Wind load and weight during the assembly of the wall at its incomplete fastening;

- Foot loading with the intensity $4.0 \mathrm{kN} / \mathrm{m}^{2}$ on the top surface of a wall;

- Local soil shrinkage;

- Wave impact.

In accordance with the calculation results, it is shown that there is necessity in three levels of wall fastening on the altitude and the pitch of anchor to be determined. The production of panels is realized by the vacuum infusion technology, that is why for the optimization of location of the resin injection spots, calculation of impregnation speed has been carried out.

\subsection{Testing}

For confirmation of the structure stiffness extensive experimental tests, which include definitions of strength parameters, deformability and crack resistance of used materials, has been carried out by taking into account climatic effects, trials of the main units and joints, and also the nature test of anchors pulled out of reinforced soil.

In fig. 4 the destruction of the anchors' attachment fittings under tension and compression are shown. The weakest element in fitting was a rod designated for connection of an anchor bar and panel fitting. For increase of the fitting's carrying ability the diameter of the rod was increased and strength requirements to its material were also increased. 


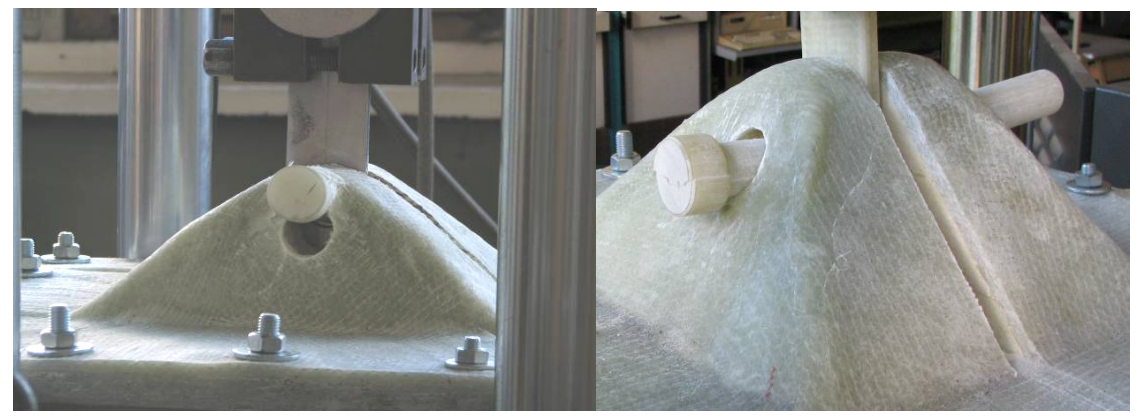

Figure 4: Destruction of the fitting under tension.

Checking of the carrying ability of fittings of anchor bars embedment at the protective sea side wall in reinforced soil was carried out on a natural sample that was assembled on the site of the wall installation from the materials designated for its manufacturing. In fig. 5(a) the procedure of the sample manufacturing is shown. The strength of the sample has three times exceeded the necessary value. Destruction has occurred not along the reinforced soil, but due to exhaustion of the carrying ability of anchors bars (fig. 5(b)).

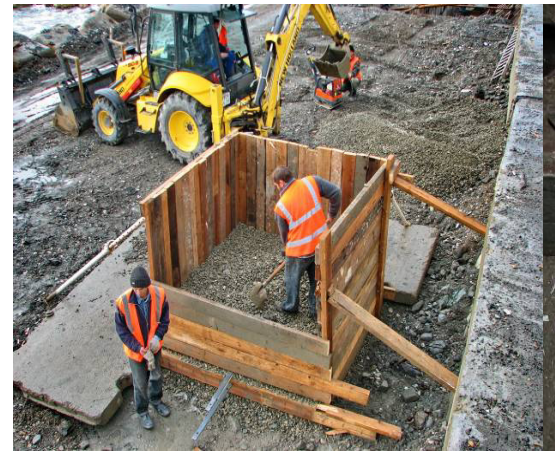

(a)

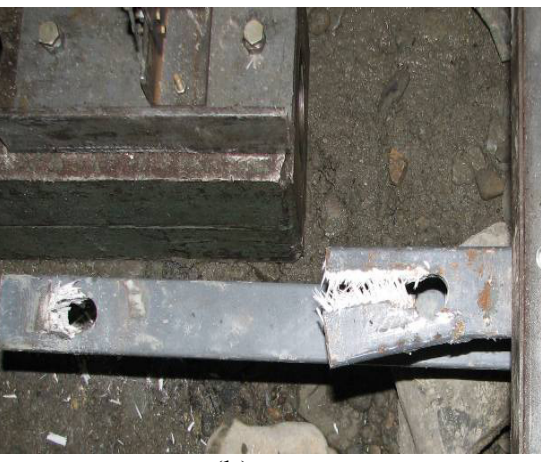

(b)

Figure 5: Assembly of the sample for testing (a) and view of breaking of anchor bars (b).

\subsection{Assembly}

The assembly of the protective wall section with a length about $80 \mathrm{~m}$ was realized within a month at the end of 2008 (fig. 6). On request of the customer the external surface was additionally covered with fire-retarding composition, as the wall is situated in a recreation area and there is a possibility of fire development near it.

The assembly of composite panels was realized by six people (fig. 7). The wall was assembled with the help of an erecting crane with low lifting ability for installation of wall panels, as the weight of the structure elements does not 


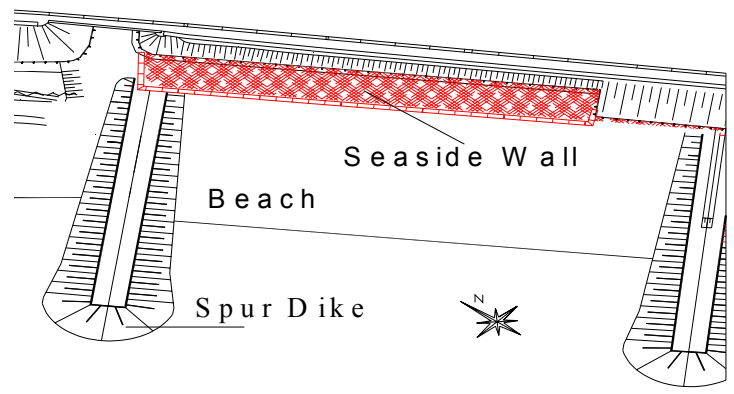

Figure 6: Scheme of protective seaside wall.

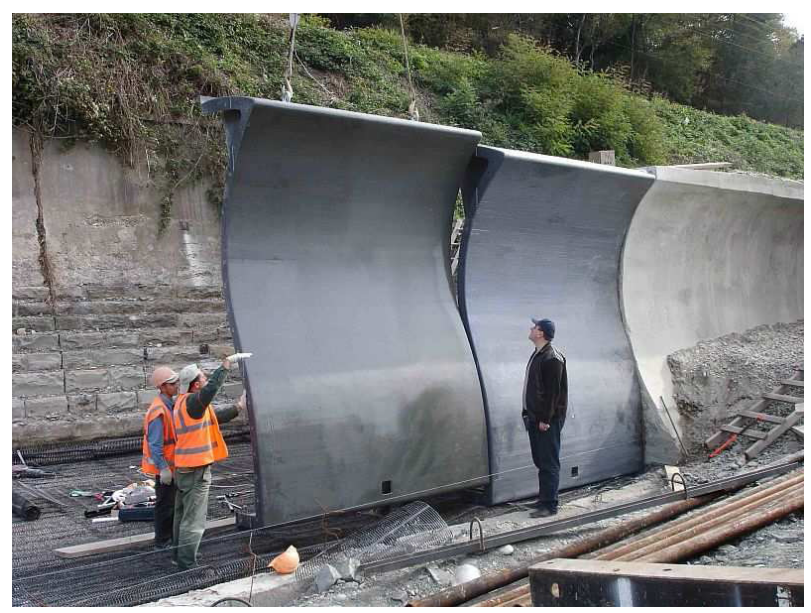

Figure 7: Assembly of protective seaside wall.

exceed 1 ton. An automotive lift truck was also used for heaping and surfacing of the embankment and beach. A vibroroller was used for the compression of the material. All the works were made without traffic interruption and speed limitation of the trains.

\section{Monitoring}

Due to the novelty of the protective wall, lack of the specific data concerning its loading and for the behavior control of the testing part of the wall during its operation has been worked out, the monitoring program which consists of 2 levels:

- Visual-geodesic - for the control of changes in the wall position

- Instrumental - for the examination of the anchors loading 
Within the first 6 months after putting the wall into operation, monitoring was realized monthly.

For the realization of instrumental monitoring all the anchor bars of joint panels were implemented by strain sensors (fig. 8). The expansion joint was in the control zone. Before the sensors' installation, a calibration at all anchors' bars was made. The sensors are protected from mechanical effects, encapsulated and designated for the work within not less than 5 years.

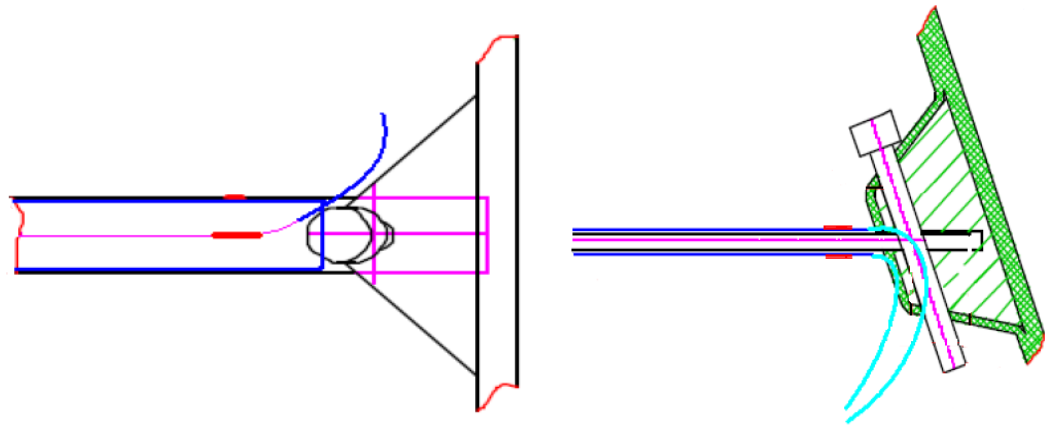

Figure 8: The scheme of the sensors gluing to the anchor bars.

After the 6 months testing the following conclusions have been made:

- All anchors of the top level work in compression (anchors thrust against the wall), the forces vary from $-1 \mathrm{kN}$ up to $-14 \mathrm{kN}$, on average the absolute force value is approximate $6 \mathrm{kN}$. We can observe a tendency of the loading diminution for all anchor bars of the level and a tendency to the forces balancing between the anchors. The maximum change in the anchor bars forces - is $4.8 \mathrm{kN}$ in a month.

- The middle level anchors work in a multidirectional way from $-14 \mathrm{kN}$ up to $28 \mathrm{kN}$. We should take into consideration that not only readings from different anchors are multidirectional but also within the time. The maximum increment within the month is $7.5 \mathrm{kN}$.

- The biggest part of the low level anchors (excluding 2 or 3 anchors) work in compression, the forces vary from $-8 \mathrm{kN}$ up to $4 \mathrm{kN}$. The maximum increment within the month is $1.7 \mathrm{kN}$.

- The maximum bending stress for the top level is $40 \mathrm{MPa}$, for the middle level is $68 \mathrm{MPa}$ and for the bottom level is $83 \mathrm{MPa}$. The stress differences in the measuring time intervals are not considerable and are in the limits of the device accuracy. That is why the appearance of bending stress is due to the assembly process and is of random nature. Taking into consideration the high level of bending stress (calculated stress of the bars material is $120 \mathrm{MPa}$ ) in future it is necessary to take into consideration its value at designing and to examine the technology of the wall assembly in order to decrease the bending stress. 
In general, it was observed that the maximum loading of axial force had a middle level of anchors, the loading of the top level is a little bit less and the lowest loading had the bottom level of anchor flange. It contradicts the main calculated positions - the loading of the level is inversely related to the height of the flange height. Loading by the bending stress corresponds to the calculated positions, but probably its level is of random nature as, for example, for the bottom level in one anchor bar the bending stresses were $83 \mathrm{MPa}$, and in others did not exceed $36 \mathrm{MPa}$. The differences between calculations and experiments are related to the following: in calculations it was considered beach destruction before the wall for the depth about 1,5 meters, but at the moment of operation the beach is at the projected level.

In fig. 9 the comparison of the anchors loading in operation and the bearing capacity of the anchors is shown, which was estimated and which we got with the help of experiments. You can see in the diagram that the experimental values exceed the calculated values at designing, but they are considerably lower than the real stiffness of the anchors. Due to this and to small loading differences of the anchors of different levels, in future during designing it is necessary to put the calculated stiffness not less than $30 \mathrm{kN}$ for all three levels of anchoring.

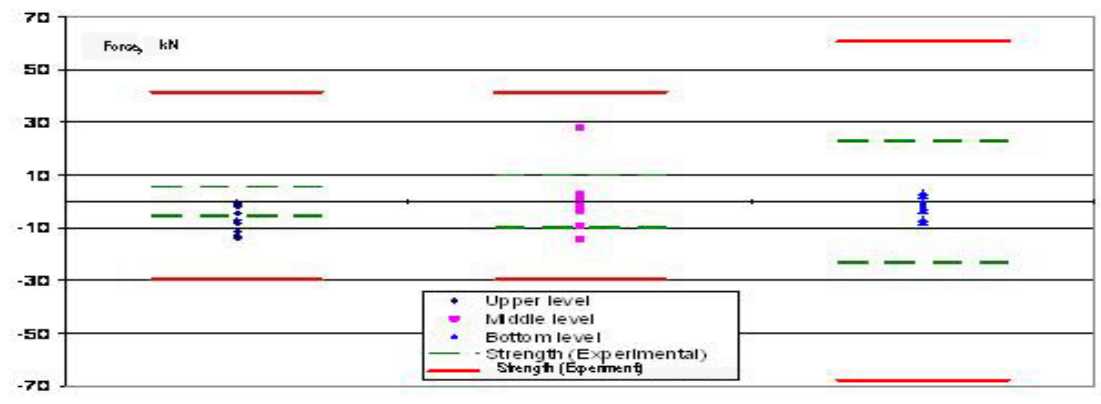

Figure 9: Diagram of the anchors bearing capacity and of measuring results in operation.

\section{Conclusion}

The complete cycle of works regarding the creation of a new structure of seaside wall with the application of composite materials, including the processes of designing, calculation and experimental researches, technology development, production, installation of a trial section and monitoring in operation has been executed. In accordance with the monitoring results the conditions of the wall loading has been precise. In general the experience of composite materials application for the protective seaside wall is quite successful and application of the structure allows:

- to substantially reduce the assembly time and labor intensity; 
- to eliminate from the works concrete and heavy-weight construction machinery;

- to decrease requirements to the materials from which the reinforced soil is formed;

- to make the assembly in almost any temperature conditions;

- to ameliorate the appearance of the structure. 